\title{
Nominal Group Technique consultation of a Pulmonary
}

\section{Rehabilitation Programme [version 1; peer review: 2}

\section{approved, 1 approved with reservations]}

\author{
Hayley A Hutchings ${ }^{1}$, Frances L Rapport ${ }^{1}$, Sarah Wright ${ }^{1}$, Marcus A Doel ${ }^{2}$, \\ Clare Clement ${ }^{1}$, Keir E Lewis ${ }^{1}$
}

1Patient and Population Health and Informatics Research (PPHI), College of Medicine, Institute of Life Sciences 2, Swansea
University, Swansea, SA2 8PP, UK
${ }^{2}$ Centre for Urban Theory, Department of Geography, Swansea University, Swansea, SA2 8PP, UK

V1 First published: 13 Feb 2014, 3:42

https://doi.org/10.12688/f1000research.3-42.v1

Latest published: 06 Aug 2014, 3:42

https://doi.org/10.12688/f1000research.3-42.v2

\section{Abstract}

Objective: The purpose of the study was to determine what patients, professionals and significant others regarded as the most important positive- and challenging aspects of Pulmonary Rehabilitation Programmes for patients with Chronic Obstructive Pulmonary Disease (COPD) and to gain insight into how such programmes could be developed and improved.

Method: A modified Nominal Group Technique method was used in three consultation workshops (one with COPD patients who had recently undertaken a Pulmonary Rehabilitation Programme; one with 'significant others' of the same patients; one with secondary care professionals who deliver the Pulmonary Rehabilitation Programme).

Results: Each of three workshops resulted in the production of approximately ten positive- and ten challenging aspects related to Pulmonary Rehabilitation Programmes. These were further developed by a process of thematisation into seven broad themes. The most important was 'the patient', followed by 'physical health'; jointly ranked as third were: 'mental health' and 'knowledge and education'. 'The programme' and 'professional characteristics' were jointly ranked as fifth, with 'the future' being ranked as the least important theme.

Conclusions: The modified Nominal Group Technique method allowed the development of a ranked thematic list that illustrated the important positive- and challenging aspects of Pulmonary Rehabilitation Programmes for patients with COPD. These themes should be core to planning future Pulmonary Rehabilitation Programmes, particularly if patients and carer views are to be considered. 


\section{Keywords}

Chronic Obstructive Pulmonary Disease, patients, professionals,

Pulmonary Rehabilitation Programme, Nominal Group Technique

Corresponding author: Hayley A Hutchings (h.a.hutchings@swansea.ac.uk)

Competing interests: No competing interests were disclosed. The study sponsor has had no involvement in the study design, collection, analysis or interpretation of data.

Grant information: This work was supported by a grant from the Hywel Dda Local Health Board Research and Development Committee (Project R\&D reference HD/12/004) and was awarded to Dr Hayley Hutchings and Professor Frances Rapport as joint principal investigators.

The funders had no role in study design, data collection and analysis, decision to publish, or preparation of the manuscript.

Copyright: (c) 2014 Hutchings HA et al. This is an open access article distributed under the terms of the Creative Commons Attribution License, which permits unrestricted use, distribution, and reproduction in any medium, provided the original work is properly cited. Data associated with the article are available under the terms of the Creative Commons Zero "No rights reserved" data waiver (CC0 1.0 Public domain dedication).

How to cite this article: Hutchings HA, Rapport FL, Wright $S$ et al. Nominal Group Technique consultation of a Pulmonary Rehabilitation Programme [version 1; peer review: 2 approved, 1 approved with reservations] F1000Research 2014, 3:42 https://doi.org/10.12688/f1000research.3-42.v1

First published: 13 Feb 2014, 3:42 https://doi.org/10.12688/f1000research.3-42.v1 


\section{Introduction}

Chronic Obstructive Pulmonary Disease (COPD) is a progressively disabling condition characterised by impaired respiratory function associated with physical limitations and psychological co-morbidity ${ }^{1}$. COPD results in a reduced capacity for functional activities and performance of daily activities with a corresponding impairment in Health Related Quality of Life ${ }^{2}$. Current figures show 900,000 people have been diagnosed with and are receiving treatment for COPD within the United Kingdom ${ }^{3}$. However, due to under reporting or under diagnosis, the actual number of those suffering with COPD is estimated to be as high as 3 million ${ }^{4}$. Stopping smoking is crucial and is the only intervention that influences the natural history of lung deterioration, with current pharmacological treatment being aimed at reducing symptoms and exacerbations ${ }^{5}$.

Pulmonary Rehabilitation Programmes are multi-disciplinary interventions individually tailored to optimise each patient's physical and social performance. Rigorous evidence from randomised controlled trials demonstrates that Pulmonary Rehabilitation Programmes for COPD can improve dyspnoea, exercise tolerance, Health Related Quality of Life, and reduce the number of days spent in hospital and the utilisation of healthcare resources ${ }^{6-8}$. Pulmonary Rehabilitation Programmes have been shown to be cost-effective and are now recommended for all patients who remain breathless despite optimal bronchodilators, irrespective of severity and age ${ }^{6-9}$. Pulmonary Rehabilitation Programmes are also being effectively applied to non-COPD causes of pulmonary impairment ${ }^{10}$.

There are now specific guidelines and recommendations in the United Kingdom regarding Pulmonary Rehabilitation Programmes, including how to select patients, the timing and number of sessions, intensity and type of exercise, the key educational, psychological and behavioural components, oxygen supplementation and outcome assessment ${ }^{7,8}$. Research exploring the benefits following Pulmonary Rehabilitation Programmes has predominantly been quantitative in nature. There have been some qualitative studies with COPD patients, but these have focused largely on specific aspects of patient experience ${ }^{11,12}$ and barriers to participation in Pulmonary Rehabilitation Programmes or other self-management programmes $^{13,14}$. There has been some exploration of the effectiveness of self-management programmes from the patient perspective ${ }^{15-17}$. However, none of these studies have combined patient, carer, and professional perspectives, particularly in an in-depth analysis regarding the long-term impact of Pulmonary Rehabilitation Programmes in relation to personal needs and issues such as perceived patient benefits, and expectations and challenges of Pulmonary Rehabilitation Programmes. It has been recognised that a better understanding of how Pulmonary Rehabilitation Programmes improve Health Related Quality of Life could affect the future design of programmes, enhance measurement tools for Health Related Quality of Life and more appropriately support the specific needs of patients ${ }^{15,17,18}$.

Consensus methods are techniques used gain opinions and views from appropriate experts regarding the current position in a particular field. They provide a mechanism for assimilating and synthesising information, particularly where published information may be inadequate or non-existent ${ }^{19}$. The purpose of consensus methods is to reach an agreement on a particular issue. Consensus methods can also mitigate some of the problems sometimes associated with group decision-making processes. In particular, where dominant views may lead the process and crowd out other perspectives ${ }^{19}$.

Nominal Group Technique is one of the commonly used consensus methods within healthcare and medical settings. The technique was first developed as an organisational planning technique by Delbecq et al. in the $1970 \mathrm{~s}^{20}$. The Nominal Group Technique normally involves four main phases: a nominal phase, during which each individual silently considers the issues under deliberation; an item-generation phase, during which each individual discloses the results of their deliberation to the group; a discussion and clarification phase, during which the group assures itself that it has understood the items that have been advanced; and a voting phase, during which the items are evaluated and the issue is decided (e.g. a ranking exercise). Nominal Group Technique promotes individual contributions allowing each individual the opportunity to voice their opinions. Factors that would normally inhibit participation are therefore avoided and even the more reticent group members are encouraged to participate in all phases ${ }^{21}$.

By adopting a mixed methods design, employing qualitative and quantitative methods during consultation with mixed stakeholder groups, and by including a modified Nominal Group Technique component as described previously ${ }^{22}$, we aimed to provide a picture of the perceived benefits and challenges of Pulmonary Rehabilitation Programmes for COPD patients. Here we report the quantitative analysis of the Nominal Group Technique activities.

\section{Methods}

Following regional ethics and research and development approval, a series of consultation workshops were held between January and December 2012, in a District General Hospital in Wales, United Kingdom, serving a mixture of urban and agricultural communities. The hospital delivers a regular Pulmonary Rehabilitation Programme which includes 18 sessions of outpatient multidisciplinary input from occupational therapists, physiotherapists, dietetics staff, physicians, specialist respiratory nurses, social workers and a smoking cessation counsellor. The content and timings of the Pulmonary Rehabilitation Programme is evidenced-based and is tailored to individual requirements and personalised goal setting.

\section{Participants}

We recruited across the South West Wales Regional Health Board, United Kingdom that serves 385,000 people and included patient, professional and significant other groups, to ensure we included a wide range of views, experience and knowledge of COPD and Pulmonary Rehabilitation Programmes.

Patients with COPD who were currently participating in or who had completed a Pulmonary Rehabilitation Programme within the last 2 years were approached to participate in the study, with most being approached in their last Pulmonary Rehabilitation Programme session. Information sheets were given to patients for their significant others (husbands, wives, partners, friends, carers or family members) inviting them to contact the researcher if they wished to participate. Professionals who were identified as playing a significant role in the delivery of the Pulmonary Rehabilitation 
Programmes and the treatment of COPD patients (occupational therapists, physiotherapists, respiratory consultants, respiratory team administrators, pharmacists, counsellors, psychologists, and specialist respiratory nurses) were also approached to participate in the study. All 20 participants ( 8 patients, 8 professionals and 4 significant others) provided written informed consent.

\section{Study design}

Our aim was to gain an understanding of the positive and challenging aspects of Pulmonary Rehabilitation Programmes for patients with COPD and to gain a consensus regarding what constitute the most important aspects of Pulmonary Rehabilitation Programmes.

\section{Consultation workshops}

Nominal Group Technique consensus exercises were carried out as one aspect of a multi-layered, mixed-method consultation during three half-day workshops (one with professionals, one with COPD patients, and one with the significant others of patients). Based on guidance in the literature for optimal numbers for qualitative group consultations, we aimed to recruit six participants to each of the three workshops ${ }^{23}$.

Each workshop was made up of three parts. Part one began with a broad discussion that examined the nature and content of Pulmonary Rehabilitation Programmes through a semi-structured group interview. The second part involved more extensive discussion with participants. Having attended a Pulmonary Rehabilitation Programme, participants were encouraged, using personal examples to describe what the Programme meant to them. This included exploring their perceived views regarding the benefits and challenges of Pulmonary Rehabilitation Programmes and impact on patient Health Related Quality of Life. An adapted Nominal Group Technique exercise was employed in the final part of the workshop. The focus of this stage was to address the following question with participants: "what are the positive, and what are the challenging aspects of Pulmonary Rehabilitation Programmes for the treatment and rehabilitation of COPD patients?" During the Nominal Group Technique exercise, issues that were raised in the early parts of the workshop were refined and condensed into a list of approximately ten positive and ten challenging aspects. At the end of the workshop, participants were asked to rank these aspects in order of significance (Steps 1-7, leading to Output 1, Figure 1). The generation of the positive and challenging aspects of the Pulmonary Rehabilitation Programme using Nominal Group Technique followed the standard approach outlined in previous work ${ }^{22}$.

The data generated from each Nominal Group Technique activity (Output 1, Figure 1) were collated for each consultation workshop. Median ranks with interquartile ranges were calculated using SPSS version 19 for each of the aspects on the positive and challenging lists and a consensus ranked list was produced based on these final median ranks.

\section{Nominal Group Technique consultation of a Pulmonary}

Rehabilitation Programme Data Set

7 Data Files

http://dx.doi.org/10.6084/m9.figshare.928540

\section{Generation of themes}

Following the consultation workshops we adapted the Nominal Group Technique method as previously described ${ }^{22}$ in order to include an additional multi-group ranking round (Steps 8-10, Figure 1). The lists of positive and challenging aspects of a Pulmonary Rehabilitation Programme produced following the three workshops were organised into a series of over-arching themes under which the positive and challenging aspects fitted (Step 8, Output 2, Figure 1). Rigour was maintained throughout the process of theme generation, by adhering to recommended qualitative data reliability and validity techniques ${ }^{24-26}$. An independent analysis of the lists generated from the workshops was carried out by two of the study team in order to identify the key over-arching themes. This process involved deletion of duplicate items and amalgamation of items where overlap was clear. A final set of common themes was independently generated by a third member of the team. This reflected and amalgamated the thematisations of the first two.

\section{Thematic consensus}

Following the generation of themes, all the original workshop participants were sent a pack of A5-sized cards. Each card carried a broad theme as a header under which were listed the associated set of positive and challenging aspects. As with the earlier workshop Nominal Group Technique activity, participants were asked to rank the themes in order of importance: with ' 1 ' representing the theme they regarded as being most important and subsequent ranks signifying the themes of diminishing importance (Step 9, Figure 1) ${ }^{22}$. The ranked cards were returned by participants in a pre-paid envelope.

The data from the returned cards were analysed using SPSS version 19 in order to calculate the median ranks and interquartile ranges (IQR) for each of the themes. A final consensus ranked thematic list was produced based on these median ranks (Step 10, Figure 1). This was the list produced for discussion and dissemination ensuring veracity within the method and enabling cross-consideration of themes and aspects by team members from Stage 1 thematisation undertaken within a group setting, to Stage 2 thematisation, undertaken by individual participants, post-consultation workshop.

\section{Thematic template generation}

Notes and audio recordings from the three consultation workshops were transcribed. These transcripts were subjected to thematic and summative analysis to extract relevant information related to each of the generated themes ${ }^{27,28}$. The detailed content relating to each theme was extracted from the individual transcripts and was built up to articulate fully the set of aspects that it contained and to clarify any anomalies or ambiguities ${ }^{29}$. The final output of the consultation workshop was a 'thematic template' that ranked each theme in order and that provided a qualitative in-depth elaboration of the content contained within each theme.

\section{Results}

\section{Consultation workshops}

We recruited a total of 20 participants across the three consultation workshops (see Table 1). Thirty three positive and 35 challenging aspects of Pulmonary Rehabilitation Programmes were produced in total for the three workshop group. The ranked list for each of the consultation workshops is illustrated in Table 2. 
1. "What are the positive and challenging aspects of Pulmonary Rehabilitation Programmes for the treatment and rehabilitation of Chronic Obstructive Pulmonary Disease patients?" Posed to three separate consultation workshops.

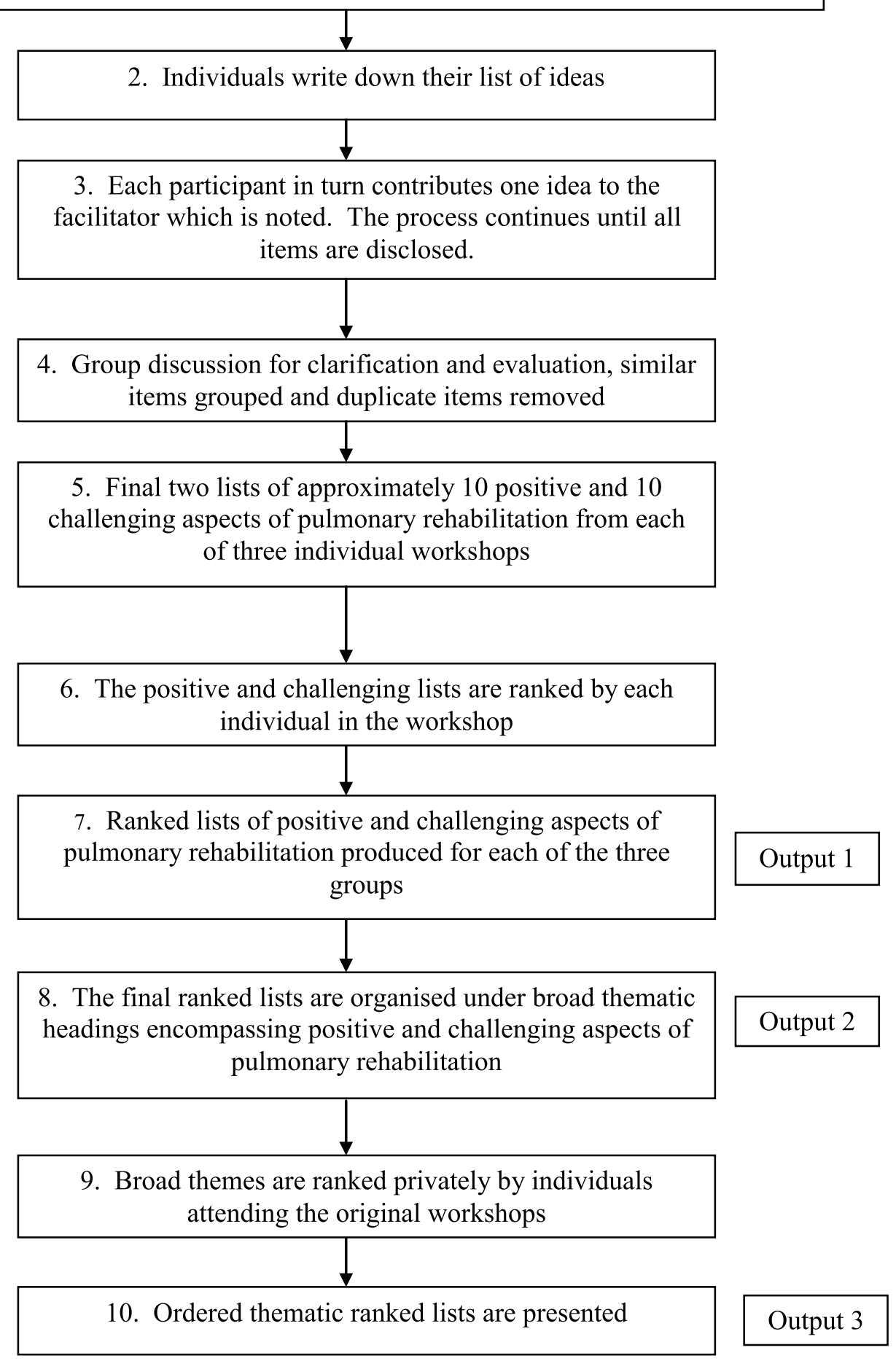

Figure 1. Flow diagram steps involved in the Nominal Group Technique process of the study. 


\section{Table 1. Summary of three Chronic Obstructive Pulmonary Disease (COPD) workshop participant samples.}

\begin{tabular}{|c|c|c|c|c|c|c|}
\hline & $\begin{array}{l}\text { Study } \\
\text { group }\end{array}$ & Male/female & Participant status & Age & $\begin{array}{l}\text { Date of PR } \\
\text { programme }\end{array}$ & $\begin{array}{l}\text { Year of } \\
\text { diagnosis }\end{array}$ \\
\hline 1 & $\mathrm{SO}$ & M & Significant other & $\mathrm{n} / \mathrm{a}$ & $\mathrm{n} / \mathrm{a}$ & $\mathrm{n} / \mathrm{a}$ \\
\hline 2 & SO & $\mathrm{F}$ & Significant other & $\mathrm{n} / \mathrm{a}$ & $\mathrm{n} / \mathrm{a}$ & $\mathrm{n} / \mathrm{a}$ \\
\hline 3 & $\mathrm{SO}$ & $\mathrm{F}$ & Significant other & $\mathrm{n} / \mathrm{a}$ & $\mathrm{n} / \mathrm{a}$ & $\mathrm{n} / \mathrm{a}$ \\
\hline 4 & $\mathrm{SO}$ & $\mathrm{F}$ & Significant other & $\mathrm{n} / \mathrm{a}$ & $\mathrm{n} / \mathrm{a}$ & $\mathrm{n} / \mathrm{a}$ \\
\hline 5 & PROF & M & $\begin{array}{l}\text { Consultant } \\
\text { respiratory physician }\end{array}$ & $\mathrm{n} / \mathrm{a}$ & $\mathrm{n} / \mathrm{a}$ & $\mathrm{n} / \mathrm{a}$ \\
\hline 6 & PROF & M & $\begin{array}{l}\text { Consultant } \\
\text { respiratory physician }\end{array}$ & $\mathrm{n} / \mathrm{a}$ & $\mathrm{n} / \mathrm{a}$ & $\mathrm{n} / \mathrm{a}$ \\
\hline 7 & PROF & M & Pharmacist & $\mathrm{n} / \mathrm{a}$ & $\mathrm{n} / \mathrm{a}$ & $\mathrm{n} / \mathrm{a}$ \\
\hline 8 & PROF & $\mathrm{F}$ & $\begin{array}{l}\text { Occupational } \\
\text { therapist }\end{array}$ & $\mathrm{n} / \mathrm{a}$ & $\mathrm{n} / \mathrm{a}$ & $\mathrm{n} / \mathrm{a}$ \\
\hline 9 & PROF & $\mathrm{F}$ & $\begin{array}{l}\text { Specialist respiratory } \\
\text { nurse }\end{array}$ & $\mathrm{n} / \mathrm{a}$ & $\mathrm{n} / \mathrm{a}$ & $\mathrm{n} / \mathrm{a}$ \\
\hline 10 & PROF & $\mathrm{F}$ & Physiotherapist & $\mathrm{n} / \mathrm{a}$ & $\mathrm{n} / \mathrm{a}$ & $\mathrm{n} / \mathrm{a}$ \\
\hline 11 & PROF & $\mathrm{F}$ & Administrator & $\mathrm{n} / \mathrm{a}$ & $\mathrm{n} / \mathrm{a}$ & $\mathrm{n} / \mathrm{a}$ \\
\hline 12 & PROF & $\mathrm{F}$ & Dietician & $\mathrm{n} / \mathrm{a}$ & $\mathrm{n} / \mathrm{a}$ & $\mathrm{n} / \mathrm{a}$ \\
\hline 13 & PT & M & COPD Patient & 73 & 2005 & 2005 \\
\hline 14 & PT & M & COPD Patient & 66 & 2010 & 2010 \\
\hline 15 & PT & $\mathrm{F}$ & COPD Patient & 54 & 2011 & 2011 \\
\hline 16 & PT & M & COPD Patient & 62 & 2011 & 2011 \\
\hline 17 & PT & M & COPD Patient & 66 & 2011 & 2009 \\
\hline 18 & PT & M & COPD Patient & 72 & 2011 & 1998 \\
\hline 19 & PT & $\mathrm{F}$ & COPD Patient & 69 & 2012 & 2005 \\
\hline 20 & PT & M & COPD Patient & 74 & 2012 & 2005 \\
\hline
\end{tabular}

SO, significant others; PROF, professionals; PT, patients; n/a, not available.

\section{Generation of themes}

Individual assimilation produced similar lists of common broad themes that were refined to seven (Output 2, Figure 1). The seven themes were: the patient, physical health, mental health, knowledge and education, the programme, professionals and significant others and the future (see Table 3).

\section{Thematic consensus}

Fourteen of the 20 attendees at the three workshops returned the packs of cards. Two were incorrectly completed, resulting in 12 evaluable responses $(60 \%)$.

Following thematic ranking, the theme that was regarded as most important was the patient, followed by physical health. Jointly ranked as third were: mental health and knowledge and education. The programme and professionals and significant others were jointly ranked as fifth, with the future ranked as the least important theme (Table 4).

\section{Thematic template generation}

In summary, the patient detailed how the patient's health and wellbeing changed for the better over the course of Pulmonary Rehabilitation, and how patients were encouraged to gain confidence, to demonstrate a commitment to improving their own health, and to adopt a broader outlook on ongoing healthcare needs and expectations. Physical health illustrated how learning to breathe "properly" had a profound impact on patients, not only because breathing well is vitally important to their health and quality of life, but also because breathing "properly" is something that needs to be learnt. Mental health highlighted that bringing patients together enabled them to appreciate that they were not alone in their feelings and experiences. Knowledge and education emphasised the ability of Pulmonary Rehabilitation Programmes to create a learning environment, lasting for many weeks, within which patients are educated about their illness, and are able to develop new techniques to manage and cope. In the programme, patients, professionals, and significant others all emphasised positive outcomes for patients attending Pulmonary Rehabilitation Programmes for the duration and in the longer-term: physically, mentally, and socially. Professionals and significant others discussed how patients regarded the professionals as "caring" and "friendly", treating them with "dignity" and "respect", and that this created a welcoming and safe environment that enabled them to feel "cared for" and "at ease". With respect to the theme of the future, participants emphasised a plethora of benefits that could be directly attributed to Pulmonary Rehabilitation Programmes, including improved health outcomes, enhanced quality of life, fewer hospital admissions, less time spent in hospital and consequently health care financial savings. 
Table 2. Positive and challenging aspects generated by each of the study workshops.

\begin{tabular}{|c|c|c|}
\hline Group & Positive aspects $(n=33)$ & Challenging aspects $(n=35)$ \\
\hline \multirow[t]{11}{*}{ Patients } & 1. Breathing properly & 1. Lack of privacy (corridor walking test) \\
\hline & 2. Breaking the cycle of inactivity & 2. Poor communication between clinicians \\
\hline & 3. Relaxation & 3. Venue not ideal (physiotherapy gym) \\
\hline & 4. Self-help; awareness; empowerment & 4. Lack of funding \\
\hline & 5. Physical benefits & 5. Explanation why there is a delay/need to wait \\
\hline & 6. Mental strength & 6. Daunting experience at the outset \\
\hline & 7. Knowledge & 7. Lack of clarity about what the programme is about \\
\hline & 8. Control panic attacks & 8. Diet information (one-sided: weight gain) \\
\hline & 9. Legacy of the future (hopes, lasting change) & 9. Commitment-insufficient for programme \\
\hline & 10. Morale, self-esteem, feel-good factor & 10. Waiting (to get on the programme) \\
\hline & & 11. Poor state of information from GPs \\
\hline \multirow[t]{12}{*}{ Professionals } & 1. Patient improvement & 1. Waiting-time lists \\
\hline & 2. Life enhancement & 2. Capacity/space constraints \\
\hline & 3. Patient improved attitude to condition & 3. Lack of flexibility to run in other locations \\
\hline & 4. Graduated exercise & 4. Time wasters/patients who do not attend \\
\hline & 5. Multi-disciplinary team approach & 5. Drop-out rate high \\
\hline & 6. Patient education/demystification/knowledge & 6. Travel and financial constraints \\
\hline & 7. Complementary/holistic - more than just a pill & 7. Convincing patients of benefits \\
\hline & 8. Good evidence base & 8. Lack of staff resources \\
\hline & 9. Validation of anxiety and confidence & 9. Lack of time to improve programme \\
\hline & 10. Patient satisfaction/appreciation of service & 10. Inability to sufficiently individualise programme \\
\hline & 11. Staff reward and motivation & 11. Long term benefits still unknown \\
\hline & & 12. Lack of follow-up \\
\hline \multirow{12}{*}{$\begin{array}{l}\text { Significant } \\
\text { Others }\end{array}$} & 1. Time for yourself & 1. Coming for the first time \\
\hline & 2. Partner's enthusiasm and enjoyment & 2. Uncertainty about what to expect \\
\hline & 3. A learning experience & 3. Challenging activities \\
\hline & 4. Gaining confidence & 4. Personal motivation to keep going \\
\hline & 5. Knowing help was available & 5. Lack of funding \\
\hline & 6. Caring staff & 6. Not knowing the bigger picture \\
\hline & 7. Given sufficient time & 7. Being over-protective \\
\hline & 8. Friendships made & 8. Learning not to take over \\
\hline & 9. Learning to manage illness & 9. Poor relationships with GPs and staff \\
\hline & 10. Physical and mental improvement and independence & 10. Lack of GP and staff knowledge \\
\hline & 11. Programme sustained & 11. Worsening of the condition in the longer term \\
\hline & 12. Saving money for the health services & 12. No opportunity for future follow-ups \\
\hline
\end{tabular}

The positive and challenging aspects within each workshop group list represent the ranked lists ordered by the individuals in each group. The aspects generated are based on direct quotes from the individuals attending the workshops.

\section{Discussion}

We identified important aspects of Pulmonary Rehabilitation Programmes for the treatment of COPD from the point of view of a mixed population group of patients, professionals and significant others. Using a modified Nominal Group Technique exercise delivered during innovative consultation workshops, we produced a novel ranked thematic list that encompassed the important positive but also challenging aspects of Pulmonary Rehabilitation Programmes.

There was a surprisingly diverse range of generated aspects (Table 2) across the three workshops. The professional outputs were focused on pragmatic service delivery, with a clear goal of patient improvement, education and attitudinal change. The patients focused not only on physical improvements but also on improving mental strength, morale and self-esteem. Although all patients were positive about Pulmonary Rehabilitation Programmes, they also highlighted the challenges faced by some of them in attending them, which included an occasional lack of privacy, instances of poor communication, inadequate venues for certain activities (e.g. a public area of a hospital corridor to perform shuttle walk tests) and being daunted by the prospect of exercise and gym work. These findings are in accord with previous literature, which has examined the reasons for non-attendance on Pulmonary Rehabilitation Programmes ${ }^{13,17}$. 
Table 3. Final themes encompassing positive and challenging aspects of Pulmonary Rehabilitation Programmes.

\begin{tabular}{|c|c|c|}
\hline Theme & Positive aspects & Negative aspects \\
\hline The Patient & $\begin{array}{l}\text { Patients gain an improved awareness and appreciation } \\
\text { of their condition } \\
\text { Patients gain confidence from attending Programme } \\
\text { Programme supports self-help and empowerment for patient } \\
\text { Programme helps patients recover aspects of everyday life } \\
\text { Patient has enjoyed the experience }\end{array}$ & $\begin{array}{l}\text { Daunting experience at outset and attending } \\
\text { Programme for the first time } \\
\text { Insufficient commitment to Programme } \\
\text { Time wasters/‘Did Not Attend' (DNAs) } \\
\text { Challenges physical ability of patients } \\
\text { Lack of personal motivation to keep going }\end{array}$ \\
\hline Physical Health & $\begin{array}{l}\text { Being able to breathe properly } \\
\text { Control anxiety and panic through relaxation } \\
\text { Family and friends using same physical techniques for } \\
\text { themselves } \\
\text { Patient experiencing improvements in own health } \\
\text { Developing more independence as result of physical } \\
\text { improvements } \\
\text { Breaking the habit of feeling physically inadequate }\end{array}$ & Physical activity \\
\hline Mental Health & $\begin{array}{l}\text { Gaining an improved attitude to the condition } \\
\text { Developing mental strength and confidence } \\
\text { Ability to live a more fulfilling life } \\
\text { Experiencing a 'feel-good' factor and increased sense of } \\
\text { self esteem } \\
\text { Perceiving improvements in one's health } \\
\text { Better state of mind }\end{array}$ & $\begin{array}{l}\text { To keep motivated and 'keep going' } \\
\text { Controlling panic attacks }\end{array}$ \\
\hline The Programme & $\begin{array}{l}\text { Programme saves health service money } \\
\text { Programme is complementary and holistic in approach - far } \\
\text { more than a 'pill' } \\
\text { Programme should be sustained } \\
\text { Gradual increase in exercise across the Programme } \\
\text { Good scientific evidence that the Programme works } \\
\text { Patient and partner satisfaction with Programme } \\
\text { Multi-disciplinary approach during Programme sessions } \\
\text { Programme provides time and independence for } \\
\text { significant other } \\
\text { Appropriate duration and frequency of Programme sessions }\end{array}$ & $\begin{array}{l}\text { Uncertainty about what the Programme entails } \\
\text { Attending Programme for the first time } \\
\text { Funding for Programme } \\
\text { Patient travel and financial constraints } \\
\text { Capacity and space for Programme } \\
\text { Limitations to running Programme in small number of } \\
\text { locations } \\
\text { Programme is not individualized enough } \\
\text { Lack of privacy } \\
\text { Inappropriately shared professional, public and patient } \\
\text { spaces (e.g. professionals eating lunch in gym) } \\
\text { High drop-out rate } \\
\text { Time wasters/‘Did Not Attend' (DNAs) } \\
\text { Lengthy waiting lists } \\
\text { Lack of time to improve Programme }\end{array}$ \\
\hline $\begin{array}{l}\text { Professionals and } \\
\text { Significant Others }\end{array}$ & $\begin{array}{l}\text { Friendships made } \\
\text { Partner's enthusiasm and enjoyment } \\
\text { Multi-disciplinary, professional team with good-skill mix } \\
\text { Caring staff } \\
\text { Motivated staff } \\
\text { Staff feeling rewarded by the Programme work } \\
\text { Programme provides time and independence for } \\
\text { significant other } \\
\text { Patients know that help is available }\end{array}$ & $\begin{array}{l}\text { Lack of staff resource } \\
\text { Poor relationships with GPs and other staff } \\
\text { Poor communication between clinicians and between } \\
\text { Trusts } \\
\text { Convincing patients of benefits of Programme } \\
\text { Explaining delays to patients of getting on Programme } \\
\text { Significant others being over-protective of patients } \\
\text { Significant others learning not to take over }\end{array}$ \\
\hline The Future & Positive legacy of Programme & $\begin{array}{l}\text { Structured follow-up is not offered } \\
\text { Worsening of condition in the future } \\
\text { Long-term benefits still unknown } \\
\text { Lack of funding } \\
\text { Sustainability of Programme } \\
\text { Post-Programme assessment is not conducted at } \\
\text { one year }\end{array}$ \\
\hline $\begin{array}{l}\text { Knowledge and } \\
\text { Education }\end{array}$ & $\begin{array}{l}\text { Programme provides knowledge and patient education } \\
\text { Good scientific evidence for running the Programme } \\
\text { Provides a learning experience for all concerned } \\
\text { Knowledge and information helps individuals to manage } \\
\text { their illness } \\
\text { Demystifies the condition } \\
\text { Being taught how to breathe properly } \\
\text { Learning how to relax } \\
\text { Patients passing on knowledge and skills gained from } \\
\text { Programme to others }\end{array}$ & $\begin{array}{l}\text { Lack of clarity at outset regarding what the Programme } \\
\text { entails } \\
\text { Lack of General Practice staff knowledge about } \\
\text { Programme to support patients } \\
\text { More dietary information required about weight loss } \\
\text { rather than just weight gain } \\
\text { Lack of clarity at outset of benefits of the Programme } \\
\text { Not being fully informed about the potential delays in } \\
\text { starting Programme }\end{array}$ \\
\hline
\end{tabular}

The positive and challenging aspects encompassed within each theme are based on direct quotes from the individuals attending the workshops. 


\begin{tabular}{|c|c|c|}
\hline $\begin{array}{l}\text { Ordered } \\
\text { rank (1-7) }\end{array}$ & Theme & $\begin{array}{l}\text { Median rank } \\
\text { (Interquartile } \\
\text { range) }\end{array}$ \\
\hline 1 & The Patient & $1(0)$ \\
\hline 2 & Physical Health & $2(1)$ \\
\hline$=3$ & Mental Health & $4(1)$ \\
\hline$=3$ & $\begin{array}{l}\text { Knowledge and } \\
\text { Education }\end{array}$ & $4(2.5)$ \\
\hline$=5$ & The Programme & $5(1.75)$ \\
\hline$=5$ & $\begin{array}{l}\text { Professionals and } \\
\text { Significant Others }\end{array}$ & $5(2.25)$ \\
\hline 7 & The Future & $7(1)$ \\
\hline
\end{tabular}

*Based on 12 evaluable responses. Total respondents $=14$ $(14 / 20=70 \%), 2$ were excluded from analysis due to incorrect completion.

Interestingly, the significant others focused on the social elements, with friendships made, caring staff and individual care contributing to the patients' gaining confidence and learning about how to manage their condition. The significant others also highlighted the knock-on-effect of allowing them to have more time for themselves and not be so protective of the patients. All participants recognised that they were unsure what the future would bring in terms of longterm health and health-care support, but were keen for continued contact with professionals, Pulmonary Rehabilitation Programmes refresher courses and for the Pulmonary Rehabilitation Programmes to be recognised as beneficial for others, and thus maintained.

The final outcome of the Nominal Group Technique exercise was a ranked list of seven themes (Table 3), with 'the patient' ranked as the most important theme, followed by 'physical health'. Overall, the main positive benefits of Pulmonary Rehabilitation Programmes were that they instilled confidence, enabled patients to breathe properly and manage their health more efficiently, encouraged the patient to be more self-sufficient and in control, and were enjoyable. The challenges to participation were that Pulmonary Rehabilitation Programmes were daunting, physically challenging, and required motivation. Interestingly, many of these challenges have been highlighted in previous qualitative studies ${ }^{16}$ with COPD patients as important reasons why patients decline entry or withdraw from Pulmonary Rehabilitation Programmes. Patient beliefs about Pulmonary Rehabilitation Programmes can comprise positive aspects (e.g. that they will lead to improvement, safe and multidisciplinary setting, and motivation) as well as negative aspects (they lead to disruption of normal routine, being tired, transport issues and limited privacy $)^{13}$. It has been shown that attending a Pulmonary Rehabilitation Programme is associated with better management of breathlessness, which in turn has a positive impact on physical and social activity, coping strategies and patient confidence ${ }^{15,17,18}$.

This study was carried out within one geographical location in South-West Wales, United Kingdom, and employed only three consultation workshops. Whilst we are confident that the methods adopted are transferable, in line with our extensive engagement with the methods in a range of community and primary care settings ${ }^{22,30}$, a larger study, employing more consultation workshops conducted over a larger geographical area is necessary to consider whether all the important aspects of Pulmonary Rehabilitation Programmes have been revealed, and whether the themes we identified within this study are generalisable.

The adapted Nominal Group Technique exercise was a mechanism for distilling the important aspects of Pulmonary Rehabilitation Programmes in a mixed group of individuals, which allowed the views of all the participating groups to be considered as equal. The process of qualitative elaboration of these themes in terms of what they meant to patients, professionals and significant others, provided a more comprehensive picture than other studies have derived. Moreover, combining qualitative with quantitative assessments provides more information, and these approaches could be used to make recommendations to improve and develop Pulmonary Rehabilitation Programmes across health-care contexts.

\section{Data availability}

Figshare: Nominal Group Technique consultation of a Pulmonary Rehabilitation Programme Data Set, doi: 10.6084/m9.figshare. $928540^{31}$

\section{Consent}

All participants provided written informed consent.

\section{Author contributions}

HH, FR, MD and SW developed the research proposal and applied for funding. $\mathrm{HH}$ and FR were joint principal investigators on the project. $\mathrm{HH}, \mathrm{FR}, \mathrm{MD}$ and SW were involved in the study consultation workshops. All authors were involved in the analysis and presentation of the study data. HH led on writing the manuscript. FR, $\mathrm{MD}, \mathrm{CC}$ and SW provided input to and reviewed all drafts of the manuscript.

\section{Competing interests}

No competing interests were disclosed. The study sponsor has had no involvement in the study design, collection, analysis or interpretation of data.

\section{Grant information}

This work was supported by a grant from the Hywel Dda Local Health Board Research and Development Committee (Project R\&D reference HD/12/004) and was awarded to Dr Hayley Hutchings and Professor Frances Rapport as joint principal investigators.

The funders had no role in study design, data collection and analysis, decision to publish, or preparation of the manuscript.

\section{Acknowledgements}

We would like thank all of the study participants for giving their time and attending the workshops. We would also like to thank Carol-Anne Davies for her help in recruiting COPD patients and significant others, and Vicky Davies for her administrative support. 
1. Kelly C, Lynes D: Psychological effects of chronic lung disease. Nurs Times. 2008; 104(47): 82-85.

PubMed Abstract

2. Ståhl E, Lindberg A, Jansson SA, et al.: Health-related quality of life is related to COPD disease severity. Health Qual Life Outcomes. 2005; 3: 56. PubMed Abstract | Publisher Full Text | Free Full Text

3. Healthcare Commission. Clearing the air: a national study of chronic obstructive pulmonary disease. London: Commission for Healthcare Audit and Inspection. 2006. Reference Source

4. Stang P, Lydick E, Silberman C, et al:: The prevalence of COPD: using smoking rates to estimate disease frequency in the general population. Chest. 2000; 117(5 Suppl 2): 354S-9S.

PubMed Abstract | Publisher Full Text

5. Global initiative for chronic obstructive lung disease. Global strategy for the diagnosis, management, and prevention of chronic obstructive pulmonary disease. 2013 Reference Source

6. Nici L, Donner C, Wouters E, et al:: American Thoracic Society/European Respiratory Society statement on pulmonary rehabilitation. Am J Respir Crit Care Med. 2006; 173(12): 1390-413.

PubMed Abstract | Publisher Full Text

7. Ries AL: Pulmonary rehabilitation: summary of an evidence-based guideline. Respir Care. 2008; 53(9): 1203-7. PubMed Abstract

8. National Institute for Health and Clinical Excellence. Management of chronic obstructive pulmonary disease in adults in primary and secondary care. London, 2011. Reference Source

9. Lacasse $\mathrm{Y}$, Goldstein R, Lasserson TJ, et al:: Pulmonary rehabilitation for chronic obstructive pulmonary disease. Cochrane Database Syst Rev. 2006: (4): CD003793.

PubMed Abstract | Publisher Full Text

10. Hill NS: Pulmonary rehabilitation. Proc Am Thorac Soc. 2006; 3(1): 66-74. PubMed Abstract | Publisher Full Text

11. Barnett $\mathrm{M}$ : Chronic obstructive pulmonary disease: a phenomenological study of patients' experiences. J Clin Nurs. 2005; 14(7): 805-12. PubMed Abstract | Publisher Full Text

12. Rodgers S, Dyas J, Molyneux AW, et al:: Evaluation of the information needs of patients with chronic obstructive pulmonary disease following pulmonary rehabilitation: a focus group study. Chron Respir Dis. 2007; 4(4): 195-203. PubMed Abstract | Publisher Full Text

13. Fischer MJ, Scharloo M, Abbink JJ, et al.: Participation and drop-out in pulmonary rehabilitation: a qualitative analysis of the patient's perspective. Clin Rehabil. 2007; 21(3): 212-21. PubMed Abstract | Publisher Full Text

14. Keating A, Lee A, Holland AE: What prevents people with chronic obstructive pulmonary disease from attending pulmonary rehabilitation? A systematic review. Chron Respir Dis. 2011; 8(2): 89-99. PubMed Abstract | Publisher Full Text

15. Monninkhof $\mathrm{E}$, van der $\mathrm{Aa} \mathrm{M}$, van der Valk $\mathrm{P}$, et al: : A qualitative evaluation of a comprehensive self-management programme for COPD patients: effectiveness from the patients' perspective. Patient Educ Couns. 2004; 55(2): 177-84. PubMed Abstract | Publisher Full Text

16. Bulley C, Donaghy M, Howden S, et al:: A prospective qualitative exploration of views about attending pulmonary rehabilitation. Physiother Res Int. 2009;
14(3): 181-92.

PubMed Abstract | Publisher Full Text

17. Williams V, Bruton A, Ellis-Hill C, et al:: The effect of pulmonary rehabilitation on perceptions of breathlessness and activity in COPD patients: a qualitative study. Prim Care Respir J. 2010; 19(1): 45-51. PubMed Abstract | Publisher Full Text

18. Camp PG, Appleton J, Reid WD: Quality of life after pulmonary rehabilitation: assessing change using quantitative and qualitative methods. Phys Ther. 2000; 80(10): 986-95. PubMed Abstract

19. Jones J, Hunter D: Consensus methods for medical and health services research. BMJ. 1995; 311(7001): 376-80.

PubMed Abstract | Publisher Full Text | Free Full Text

20. Delbecq AL, van de Ven AH: A group process model for problem identification and program planning. Applied Behavioural Science. 1971; 7(4): 466-91. Publisher Full Text

21. Chapple M, Murphy R: The nominal group technique: Extending the evaluation of students' teaching and learning. Assessment and Evaluation in Higher Education. 1996; 21(2): 147-60. Publisher Full Text

22. Hutchings $\mathrm{H}$, Rapport $\mathrm{F}$, Wright $\mathrm{S}$, et al: Obtaining consensus about patientcentred professionalism in community nursing: nominal group work activity with professionals and the public. J Adv Nurs. 2012; 68(11): 2429-42. PubMed Abstract | Publisher Full Text

23. Bloor M, Frankland J, Thomas M, et al.: Focus Groups in Social Research. London: Sage Publications Ltd, 2001. Reference Source

24. Silverman D: Validity and credibility in qualitative research. In: Miller G, Dingwall $\mathrm{R}$, editors. Context and method in qualitative research. The alternative paradigm. London: Sage, 1997; 12-25. Reference Source

25. Pope C, Ziebland S, Mays N: Qualitative research in health care. Analysing qualitative data. BMJ. 2000; 320(7227): 114-6. PubMed Abstract | Publisher Full Text | Free Full Text

26. Seale C, Silverman D: Ensuring rigour in qualitative research. Eur J Public Health 1997; 7(4): 379-84 Publisher Full Text

27. Braun V, Clarke V: Using thematic analysis in psychology. Qual Res Psychol. 2006; 3(2): 77-101. Publisher Full Text

28. Rapport F: Summative Analysis: A qualitative method for social science and health research. Int J Qual Methods. 2010; 9(3): 270-90. Reference Source

29. Ryan GW, Bernard HR: Data management and analysis methods. In: Denzin NK, Lincoln YS, editors. Handbook of qualitative research. 2nd ed. London: Sage, 2000; 769-803. Reference Source

30. Hutchings HA, Rapport FL, Wright S, et al:: Obtaining consensus regarding patient-centred professionalism in community pharmacy: nominal group work activity with professionals, stakeholders and members of the public. Int J Pharm Pract. 2010; 18(3): 149-58. PubMed Abstract | Publisher Full Text

31. Hutchings HA, Rapport FL, Wright S, et al:: Nominal Group Technique consultation of a Pulmonary Rehabilitation Programme. Figshare. 2014. Data Source 


\section{Open Peer Review}

\section{Current Peer Review Status:}

\section{Version 1}

Reviewer Report 26 June 2014

https://doi.org/10.5256/f1000research.3790.r5251

(C) 2014 Stears A. This is an open access peer review report distributed under the terms of the Creative Commons Attribution License, which permits unrestricted use, distribution, and reproduction in any medium, provided the original work is properly cited.

\section{Amanda Stears}

Department of Physiotherapy, School of Health Sciences, Queen Margaret University, Edinburgh, Scotland, UK

The article gives a clear introduction to the concept of Pulmonary Rehabilitation (PR) acknowledging the evidence supporting the intervention and the positive impact that is has on participants lives post programme. Most importantly, it seeks to gather the opinions of "significant others" and professionals within the clinical team, something that is often overlooked but that could be a key component in service development.

There is a clear introduction to the use of the Nominal Group Technique and its usefulness in facilitating all participants' views to be gathered and the aim of providing a rank of perceived benefits and challenges in pulmonary rehabilitation is clearly stated.

The authors have used the Nominal Group Technique successfully to provide a useful ranking of themes and challenges from the perspectives of patients, professionals and significant others. These are useful to challenge current assumptions within Pulmonary Rehabilitation Programmes, but the study would benefit from consideration of the socio-demographics of the group as these also impact on health related outcomes. The small sample size also makes it difficult to generalise to a wider population, something which the authors themselves acknowledge. There is also a strong male bias in the sample group, what affect did this have on the results?

The data and techniques used are clearly described and well presented and are representative and reflective of findings in the clinical setting.

In conclusion, going forwards further research is required to establish whether the rankings are concurrent across the country, and if so do they have a role in guiding PR and assisting patients and significant others in overcoming the perceived barriers. Many of the themes and issues identified are already known to those working within the clinical setting and are addressed through education and management within PR in the UK already. There are also assumptions in practice that patients "Learn" as is stated on page 6 in the Thematic Template generation. How is this evidenced? One finding that the authors also highlight is that significant others have more 
time for themselves as patients become more independent therefore supporting the self management of PR; this would benefit from further exploration.

Competing Interests: No competing interests were disclosed.

\section{I confirm that I have read this submission and believe that I have an appropriate level of expertise to confirm that it is of an acceptable scientific standard.}

Author Response 22 Jul 2014

Hayley Hutchings, Swansea University, Swansea, UK

Thank you for these helpful comments. We have made some amendments to the manuscript on the basis of these comments which we hope will serve to clarify some of the issues raised.

Competing Interests: None

Reviewer Report 08 April 2014

https://doi.org/10.5256/f1000research.3790.r4411

(C) 2014 Camp P et al. This is an open access peer review report distributed under the terms of the Creative Commons Attribution License, which permits unrestricted use, distribution, and reproduction in any medium, provided the original work is properly cited.

Pat G. Camp

Department of Physical Therapy, University of British Columbia, Vancouver, BC, Canada

Carmen Sima

Department of Physical Therapy, University of British Columbia, Vancouver, BC, Canada

STUDY PURPOSE

The purpose of the present study was to describe the perceived benefits and challenges of pulmonary rehabilitation program for patients with COPD from the point of view of patients, professionals, and significant others (carers).

\section{TITLE AND ABSTRACT}

The title reflects the content of the article. The abstract provides a suitable summary of the work. The conclusion would be strengthened by a main message.

\section{INTRODUCTION}

The introduction provides detailed information about the area of research, gaps in the literature, and techniques employed to answer the research question. The references to the relevant literature on the mixed method design were also provided in order to support the proposed methodology. 


\section{METHODS}

The design of the study was also described clearly, including thematic generation and consensus, as well as responsibilities for integration. However, the authors state that the focus is on the quantitative analysis rather than the qualitative analysis, yet the analysis described appears to be qualitative in nature, and the authors comment on the need to maintain qualitative rigour throughout the study. A ranking by median scores by the participants is still qualitative in nature. If the intent is to undertake a quantitative analysis of the data, the selection of the median rank and interquartile ranges as appropriate statistical tests that is meant to answer the study research question seems insufficient. The authors might want to explore the differences between the different groups in regard to the perceived benefits and challenges of pulmonary rehabilitation program for patients with COPD. We consider that there is a need for clearly stating the hypothesis being tested and a motivation for selecting specific statistical analysis, should a quantitative analysis be intended. The individual data table would be better presented in the results section.

\section{RESULTS}

The results section is appropriately explained, but the emphasis is again placed on the qualitative than quantitative research findings. In addition, the authors state that 20 participants were initially included in the study ( 8 patients, 8 professionals and 4 others) and 12 participants were finally included in the analysis. Given the small sample size, there is also a need to specify the status of the participants who did not complete the study. This information may influence the interpretation of the study results. There is also a disagreement between the evaluable responses across the paper: $60 \%$ on the page 6 versus $70 \%$ on the page 9 . The authors also state that COPD patients who were currently participating in or completed a pulmonary rehabilitation program within the last 2 years were approached to participate in the study. However, Table 1 shows 2005 as year of PR program for one COPD patient. It is also worth mentioning the weak participation of physiotherapists in this study, although the pulmonary rehabilitation program was the main component of this research and the physiotherapists play a significant role in the delivery of pulmonary rehabilitation program. The thematic template generation does not offer clear guidance to the reader on what are the clear benefits and challenges - the list is somewhat selfevident and simplistic, and appears to focus on the benefits of the pulmonary rehabilitation program, but the challenges are not clearly articulated.

\section{DISCUSSION}

The conclusions are generally balanced and justified, although special emphasis is placed on the qualitative findings. Some of the discussion would be better suited to the results. The main benefits and challenges of pulmonary rehabilitation for patients, carers, and professionals as presented in the themes are not specific enough to be of use for making recommendations for improving the pulmonary rehabilitation program.

Competing Interests: Pat Camp is a member of the Canadian Thoracic Society COPD Clinical Assembly and is involved in the development of guidelines for use in COPD.

We confirm that we have read this submission and believe that we have an appropriate level of expertise to confirm that it is of an acceptable scientific standard, however we have significant reservations, as outlined above. 
Author Response 22 Jul 2014

Hayley Hutchings, Swansea University, Swansea, UK

We would like to thank the reviewers for their helpful comments. We have now made some changes to the original manuscript to help clarify some of the issues, or to highlight the limitations of the research. In addition we have responded to some of the specific queries below.

The purpose of NGT is to employ quantitative and qualitative methods in order to gain a common consensus regarding the relative importance of generated issues. The findings are developed corroboratively using combined qualitative and quantitative approaches. The 'quantitative' analysis is a simple process whereby the most favoured rank is selected as being the most important. We have presented this prioritisation as the median rank with IQR as this is statistically more appropriate for small groups of data and better illustrates the range of ranks (i.e. the variability within the group) alongside the final priority list. We have followed the standard methodological approach for this analysis of ranking. NGT is not intended to be a specific statistical analysis method in this context, but rather a method for identifying broad priorities. The final prioritisation list produced may be subject to further debate, but the statistical approach used facilitates a starting point for further exploration. We extended the traditional NGT method by employing a further thematic stage which was designed to explore the more detailed rationale for the prioritised list generated. Although this has only been presented in simple terms in this paper, we generated an in depth template for each theme which elaborated upon the issues raised. It is beyond the scope of this paper to illustrate the in depth findings and these will be reported separately. The extended qualitative findings further explore the differences between groups in more detail, but we have tried to illustrate this briefly in this paper in Table 2 which lists the positive and challenging aspects across each of the groups.

We feel that as the purpose of the paper is to present the consensus views rather than individual workshop findings, that these data tables are best appended in the data files rather than in the main results section.

Everyone linked to the pulmonary rehabilitation programme in the two hospitals was invited to and participated in the workshops. It was our aim to gather views from those individuals running the programme at the Trust rather than physiotherapists who may have been involved in delivery of PR programmes elsewhere. We were not therefore in a position to invite more physiotherapists to the workshop as all those involved in delivery attended a workshop. The hospital ran a multi-disciplinary team approach to the delivery of the PR programme and we had representation from every aspect. No health professionals were excluded.

Competing Interests: None 
(C) 2014 Bullen K. This is an open access peer review report distributed under the terms of the Creative Commons Attribution License, which permits unrestricted use, distribution, and reproduction in any medium, provided the original work is properly cited.

\section{Kate Bullen \\ Department of Psychology, Aberystwyth University, Wales, UK}

This is an interesting and useful article that explores the implications and lived experience of people dealing with the challenges of a debilitating chronic disease (COPD). This is not a "sexy" area of health care research but it is an important one as COPD substantially limits life in both quantity and quality. As such it is a worthy area of investigation, as the aim of this article is to identify how to improve the delivery of service for a sometimes overlooked patient group.

The article is well presented and reflects a high level of attention to detail in design and analysis. The research team has identified an appropriate method of investigation which is sufficiently novel to generate new knowledge that will potentially inform clinical practice. Details of the data collection and analysis processes are well presented and the data are discussed comprehensively. The research team acknowledges that there are limitations in the study in terms of the level of participants, and the level of geographical specificity of the study. Whilst this is a sensible approach such caveats should not detract from the potential value of the study for practitioners who deliver such programmers. Finally, the conclusions are well balanced and insightful with a clear pathway to future research identified.

Competing Interests: No competing interests were disclosed.

\section{I confirm that I have read this submission and believe that I have an appropriate level of expertise to confirm that it is of an acceptable scientific standard.}

The benefits of publishing with F1000Research:

- Your article is published within days, with no editorial bias

- You can publish traditional articles, null/negative results, case reports, data notes and more

- The peer review process is transparent and collaborative

- Your article is indexed in PubMed after passing peer review

- Dedicated customer support at every stage

For pre-submission enquiries, contact research@f1000.com 